\title{
CHARACTERIZATION OF MFI ZEOLITE MEMBRANES BY MEANS OF PERMEABILITY DETERMINATION OF NEAR CRITICAL AND SUPERCRITICAL $\mathrm{CO}_{2}$
}

\author{
L. SILVA', A. PLAZA', J. ROMERO' ${ }^{*}, J . S A N C H E Z^{2}, A N D$ G. M. RIOS ${ }^{2}$ \\ 1) Departamento de Ingeniería Química, Universidad de Santiago de Chile (USACH), Santiago - Chile \\ 2) Institut Européen des Membranes (UMR 5635, CNRS/ENSCM/UM2), Montpellier - France \\ (Received: 10 April 2007 - Accepted: 11 January 2008)
}

\begin{abstract}
Zeolites are inorganic materials with intrinsic microporous properties. Basically they are aluminasilicates constituted from a three dimensional network of $\mathrm{SiO}_{4}$ and $\mathrm{AlO}_{4}$ tetrahedra. This type of materials may have very interesting applications like adsorbents or molecular sieves. In this study, mass transfer properties of supported MFI zeolite membranes at high pressure are established using a new experimental methodology.

The aim of this study was the analysis of the mass transfer of a compressed carbon dioxide through microporous zeolite membranes in order to characterize its structural parameters, identifying mass transfer mechanisms under high pressure conditions. This type of materials can be used like molecular sieves, since they present a crystalline structure with interstitial micropores of a mean pore diameter of $0.55 \mathrm{~nm}$. For this purpose, we studied the mass transfer of high pressure $\mathrm{CO}_{2}$ through microporous MFI zeolite membranes using a new experimental methodology in order to determine the permeance of carbon dioxide using an original apparatus operating in transient state. Carbon dioxide is used in experiments taking into account several applications reported in the literature coupling recovery or separation of this compound from gaseous solutions with inorganic molecular sieves.

Values of flux $\left(\mathrm{mol} \mathrm{m}^{-2} \mathrm{~s}^{-1}\right)$ and permeance $\left(\mathrm{mol} \mathrm{m}^{-2} \mathrm{~s}^{-1} \mathrm{~Pa}^{-1}\right)$ have been obtained experimentally. This new experimental device allows estimating permeance values between $3.59_{*} 10^{-9}$ and $7.51_{*} 10^{-7} \mathrm{~mol} \mathrm{~m}^{-2} \mathrm{~s}^{-1} \mathrm{~Pa}^{-1}$ ) when the values of feed pressure are ranged between 3 and $14 \mathrm{MPa}$ and the temperature varies between 25 and $100^{\circ} \mathrm{C}$. These values are coherent with the microscopic nature of pores, showing that the zeolite layer deposed on the macroporous support was synthesized without macroporous defaults.

An activated diffusion through the micropores might be identified in the gas phase, but under supercritical conditions $\left(\mathrm{P}>\mathrm{P}_{\mathrm{c}}, \mathrm{T}>\mathrm{T}_{\mathrm{c}}\right)$ an irreversible modification of transport properties was observed. This behavior was explained by a limited mechanical resistance of the membrane at high pressure conditions. In supercritical conditions, mass transfer could be controlled by a combination of diffusion through mesoscopic and microscopic porosity.
\end{abstract}

Keywords: Zeolite, microporous materials, supercritical fluids, mass transfer, permeability, high pressure

\section{INTRODUCTION}

\subsection{Applications coupling microporous materials and supercritical} fluids.

A microporous material is defined by IUPAC as a porous solid with pore diameter less than 2 nanometers. This size of pores allows using this type of material for different applications involving molecular scale separations. Different crystalline materials are being used to synthesize highly selective membranes and molecular sieves. These solids with small intercrystalline pores represent an excellent homogeneous medium, which could be used for different applications where the separation of compounds with low molecular weights is necessary.

Structural parameters of different types of microporous materials are reported in the literarure, and their properties for mass transfer of gases and liquids at low pressure conditions are relatively known in function of its structure. Nevertheless, transport properties of microporous materials at high pressure conditions have not been widely studied. In this work, we report a new method to characterize mass transfer properties and structural parameters of microporous materials at high pressure, especially when a near critical or supercritical fluid is used.

A pure component is considered to be in a supercritical state if its temperature and its pressure are higher than the critical values. At critical conditions for pressure $\left(\mathrm{P}_{c}\right)$ and temperature $\left(\mathrm{T}_{c}\right)$, as indicated in figure $\mathbf{1}$ by the broken and hatched lines, there is no sudden change of component properties 1

The variation of properties with conditions of state is monotonous, when crossing the broken lines in the figure 1, with exception of the critical point itself. Yet the magnitude of the variation can be tremendous, thereby causing different effects on solutes and reactants within neighboring conditions of state. Similar effects to that of the supercritical state may in some cases be achieved for $\mathrm{P}>\mathrm{P}_{\mathrm{c}}$ and $\mathrm{T}<\mathrm{T}_{\mathrm{c}}$, at near-critical temperatures in the liquid state.

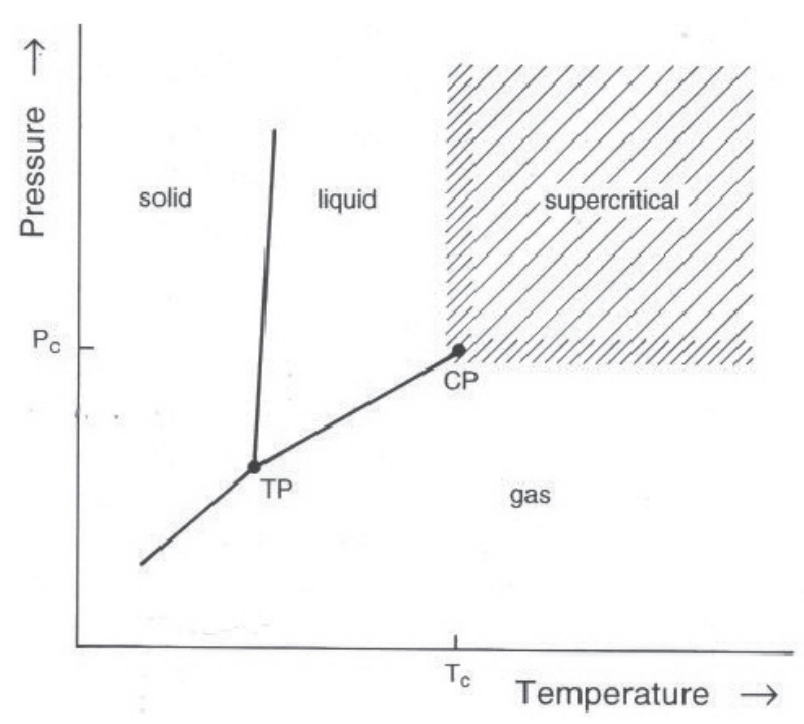

Figure 1. Definition of supercritical condition for a pure component. CP: critical point, $\mathbf{T P}$ : triple point, $\mathbf{P}_{\mathbf{c}}$ : critical pressure, $\mathbf{T}_{\mathbf{c}}$ : critical temperature.

Supercritical fluids (SCFs) are used in several processes as solvents for extraction of compounds with a low molecular weight, particle design, formation of thin films and fibers, reactions, and chromatography. Carbon dioxide is the most commonly used supercritical fluid. The supercritical $\mathrm{CO}_{2}\left(\mathrm{SC} \mathrm{CO}_{2}\right)$ presents many advantages because it is not expensive, it is chemically inert, non toxic, non flammable and it has a relatively low critical point $\left(\mathrm{P}_{\mathrm{c}}=7.38 \mathrm{MPa} ; \mathrm{T}_{\mathrm{c}}=304.15 \mathrm{~K}\right)$. In the supercritical environment only one phase exists. The fluid, as it is termed, is neither a gas nor a liquid and is best described as intermediate to the two extremes. This phase retains solvent power approximating liquids, as well as the transport properties common to gases.

A new field of chemistry and chemical engineering has been opened and therefore processes coupling supercritical fluids and microporous materials could be developed. Several membrane applications coupled to supercritical $\mathrm{CO}_{2}$ extraction $\left(\mathrm{SC} \mathrm{CO}_{2}\right)$ have been reported in the literature ${ }^{1}$ : 
- Solvent recovery or separation of $\mathrm{CO}_{2}$ from a complex mixture using filtration ${ }^{2}$, - $\mathrm{CO}_{2}$ extraction coupled with cross-flow filtration ${ }^{3}$,

- $\mathrm{CO}_{2}$ fluidification of viscous fluids during crossflow filtration ${ }^{1}$,

- Membrane contactor/reactor working under $\mathrm{SC} \mathrm{CO}_{2}$ conditions ${ }^{4}$,

Solvent recovery or separation of $\mathrm{CO}_{2}$ from complex mixtures should be a very interesting alternative to reducing the energy requirements in the solvent cycle in a conventional supercritical fluid extraction (SFE) operation. In this way, SFE can be associated to a nanofiltration process to regenerate $\mathrm{SC} \mathrm{CO}_{2}$ without depressurization and repressurization steps. Sartorelli and Brunner ${ }^{3}$ have proposed the modification of the solvent cycle in a SFE process, introducing a nanofiltration step to reduce the operation costs represented by the compression of $\mathrm{CO}_{2}$.

On the other hand, different authors ${ }^{1,5,6,7}$ have analysed the mass transfer of dense $\mathrm{CO}_{2}$ or mixtures containing $\mathrm{CO}_{2}$ through different types of membranes. All these authors explain the mass transfer through porous media by means of different mechanisms depending on the type and structural parameters of the materials, identifying macroscopic and microscopic phenomena.

In a previous contribution ${ }^{6}$, a unified approach to characterize mass transfer of liquid, gas and supercritical carbon dioxide through microporous membranes has been presented. Nevertheless, the experimental runs required to analyse the mass transport through membranes involve complex (and generally expensive) experiments based on different devices operating in steady-state conditions. Low values of permeability involve an important variability in this type of measurements and in some cases the methods applied to macroporous materials are not applicable to a microporous media.

In this study we describe a new methodology to estimate the permeability of gas, liquid, critical and supercritical fluids through MFI zeolite membranes and the interpretations of these results in function of its structural parameters.

\section{MECHANISMS OF MASS TRANSFER IN MICROPOROUS MATERIALS}

\subsection{Zeolites and zeolite membranes}

Zeolites are inorganic substrates with intrinsic microporous properties. Basically they are crystalline aluminasilicates constituted from a three dimensional network of $\mathrm{SiO}_{4}$ and $\mathrm{AlO}_{4}$ tetrahedra ${ }^{8}$. Zeolites can be represented by empiric formulas $\mathrm{M}_{2 / \mathrm{n}} \mathrm{O}_{*} \mathrm{Al}_{2} \mathrm{O}_{3^{*}} \mathrm{SiO}_{2^{*}} \mathrm{yH}_{2} \mathrm{O}$ in which $\mathrm{n}$ is the valency of the cation $\mathrm{M}$ and where $\mathrm{x} / 2$ indicates the $\mathrm{Si} / \mathrm{Al}$ ratio (equal or larger than two). The hydrophobic / hydrophilic property of the membrane as well as its thermal stability depends on the quantity of $\mathrm{Al}$ inside the material ${ }^{9}$. The pore size depends on the cation involved in the structure: $\mathrm{Ca}^{+}, \mathrm{Na}^{+}$and $\mathrm{K}^{+}$gives $5 \AA, 4 \AA$, and $3 \AA$ respectively ${ }^{8}$.

The synthesis of zeolite membranes with a low content of alumina (MFI) has been extensively reported. These membranes have been manufactured on stainless steel supports presenting a thickness of $50 \mu \mathrm{m}$ or have been synthesised inside the pores of $\alpha-\mathrm{Al}_{2} \mathrm{O}_{3}$ substrates $(100-200 \mathrm{~nm})$ resulting on zeolite layers of about 30 to $50 \mu \mathrm{m}$. Attll the authors have used the hydrothermal crystallisation for the in-situ synthesis of zeolites $8,10,11$. The gas transport through these membranes can be ensured not only by the intracrystalline diffusion but also by the intercrystalline diffusion including through mesoporous defects between the zeolite and alumina crystals. Figure 2 shows the crystalline structure of a MFI zeolite.
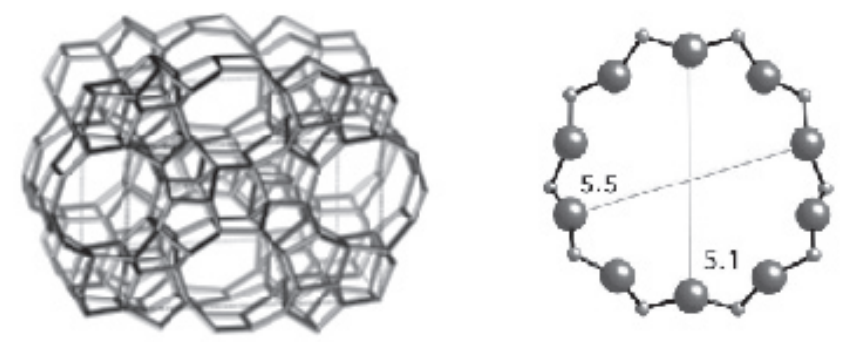

Figure 2. Three dimensional network of a MFI zeolite and its intracrystalline diameter (Angstrongs).

In relation to what has been previously said concerning the potential defects of zeolite membranes, we have chosen to characterise at first the exact contribution of the viscous flow (Poiseuille) to the total SCF flow. Then, the theory of transport through a microporous solid, quite complex due to the large number of mechanisms that are able to interfere at the same time, will be introduced.

Zeolite membranes used in this study have been formed by hydrothermal sysnthesis ${ }^{18}$. From this treatment it has been possible to prepare composite MFI/ $\alpha-\mathrm{Al}_{2} \mathrm{O}_{3}$ zeolite membranes in which most of the zeolite material was grown in situ, inside specific pores of a commercial $\alpha-\mathrm{Al}_{2} \mathrm{O}_{3}$ support (figure 3). The methodology involves a hydrothermal treatment at $175-190^{\circ} \mathrm{C}$ of a sol $\left(\mathrm{SiO}_{2} /\right.$ $\mathrm{TPAOH} / \mathrm{H}_{2} \mathrm{O}$ ) in contact with the $\alpha$-alumina tubular support (Pall-Exekia, France). The tubes have a three-layer asymmetric structure with mean pore sizes of $10,0.8$ and $0.2 \mu \mathrm{m}$. After the synthesis the template was eliminated in air at $600^{\circ} \mathrm{C}(2 \mathrm{~h})$. It can be observed that the pores of the two internal layers of the support $(0.2$ and $0.8 \mu \mathrm{m}$ pore sizes) are almost totally filled with zeolite. The grains of the external layer $(10 \mu \mathrm{m}$ pore sizes) are only partially covered with zeolite crystals. These observations are in good agreement with the mercury porosimetry analysis of the support before and after synthesis.
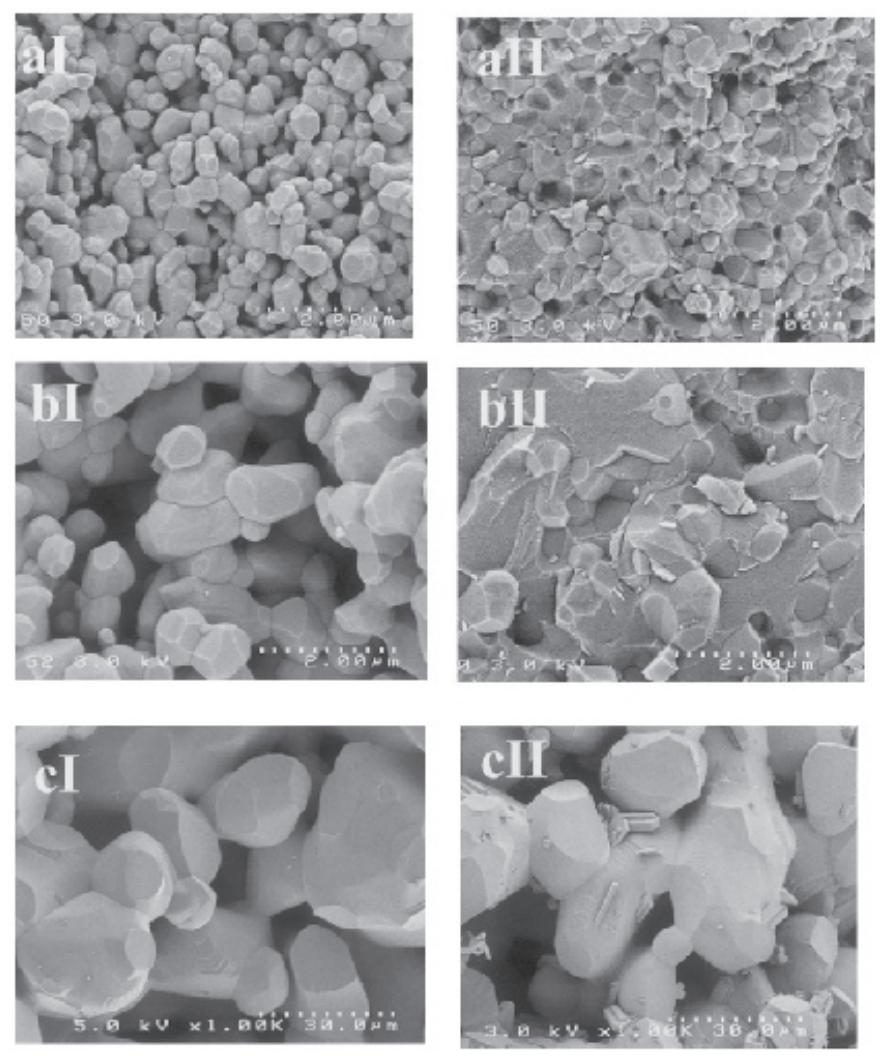

Figure 3. FESEM cross-section images of the support (Pall-Exekia): a) inner layer, b) intermediate layer, c) external layer, (I) before and (II) after MFI zeolite synthesis ${ }^{19}$.

\subsection{Mass transport mechanisms}

Some classical mass transport mechanisms through porous media may be clearly identified in macroporous and mesoporous materials, these mechanisms depend on the operation conditions and structural parameters. Figure 4 shows an outline of these different mechanisms: 

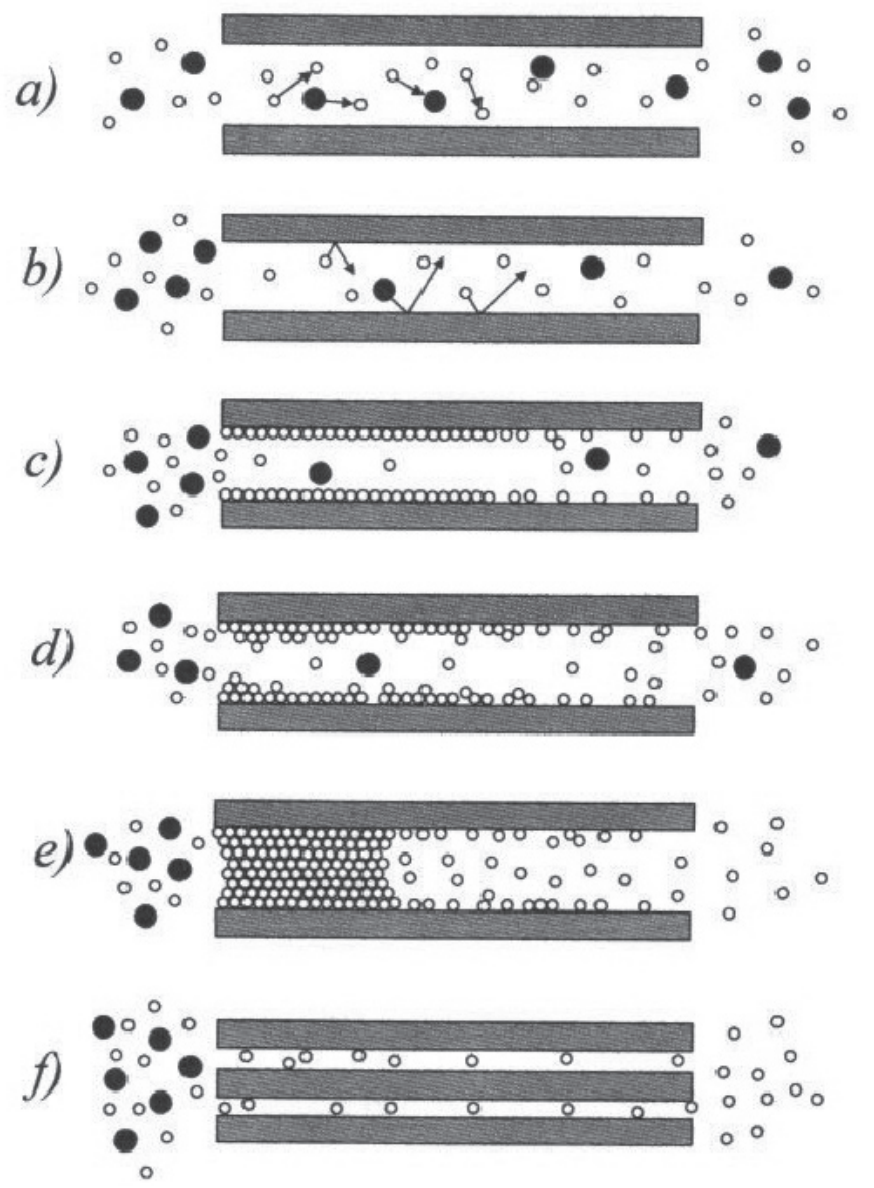

Figure 4. Mechanisms of mass transport through porous media: a) Viscous flow (Poiseuille); b) Knudsen diffusion; c) surface diffusion; d) multilayer diffusion; e) capillary condensation; f) molecular sieving ${ }^{9}$.

After having appraised the structural parameters of membranes $\left(A_{k} / \Delta z\right)$ of Titanium-Nafion, Sarrade ${ }^{12}$ applies the following equations to describe the permeance $\left(\mathrm{mol} \mathrm{m}^{-2} \mathrm{~s}^{-1} \mathrm{~Pa}^{-1}\right)$ of pure gas in Knudsen diffusion and viscous flow (Poiseuille) regimes:

$$
\begin{gathered}
G_{\text {Kudsen }}=\frac{A_{k}}{\Delta z} \cdot \frac{8 \cdot r_{y} \cdot F_{k}}{3 \sqrt{2 \cdot \pi \cdot R \cdot T \cdot M}} \\
G_{\text {Poiseuille }}=\frac{A_{k}}{\Delta z} \cdot \frac{r_{y}^{2} \cdot F_{y} \cdot P_{m}}{8 \cdot \eta \cdot R \cdot T}
\end{gathered}
$$

where $r_{p}$ is the radius of pore, $F_{k}$ and $F_{p}$ are two characteristic constants of the membrane and $\eta$ is the dynamic viscosity.

Then, in agreement with equation 1, it appears that for isobaric curves:

$$
G_{\text {Xudien }}=\frac{C_{1}}{\sqrt{T}}
$$

The same qualitative analysis on equation 2 , uses the following equation for the permeance in regime of Poiseuille:

$$
G_{\text {Poiseuille }}=\frac{C_{2}}{\eta \cdot T}
$$

Finally, at fixed temperature, $G_{\text {Knudsen }}$ does not depend on P, while:

$$
G_{\text {Poiseuille }}=C_{3} \cdot\left(\frac{P_{m}}{\eta}\right)
$$

From these equations, permeance clearly varies as a function of three variables: mean pressure, temperature and dynamic viscosity.

In microporous materials, the pore diameter is very close to the molecular diameter of the species diffusing through the porosity. Then, molecular interactions between the elementary entities of the fluid and the wall of the membrane pores should become relevant for the mass transport. In previous studies ${ }^{5,6}$, we applied a formulation based on these interactions for the modeling of supercritical $\mathrm{CO}_{2}$ transfer through microporous membranes. In those previous works, we considered at low concentration rates the following expression of flux $\left(J, \mathrm{~mol} \mathrm{~m}^{-2} \mathrm{~s}^{-1}\right)$ :

$$
J=C \cdot \exp \left(\frac{Q_{a}-E_{a}^{a}}{R T}\right)\left(P_{f}-P_{p}\right)
$$

where $C$ is a constant involving structural parameters of the membrane material (porosity, tortuosity and density) and other variables related to interactions between the fluid and membrane pore (parameters of Langmuir isotherm and diffusion coefficient).

Equation 6 shows that the flow $J$ depends on the apparent activation energy $\left(Q_{a}-E_{a}^{s}\right)$, which can be calculated directly from permeation and adsorption data. Values obtained for each parameter may define the flow evolution with the temperature increase. Equation 1 was already used by several authors to describe gas permeation in silica and zeolite membranes 9 .

Mass transport through micropores and specially in zeolites, occurs through the so-called configurational diffusion ${ }^{6}$. This intragranular diffusion depends on adsorption properties of the microporous solids and is an activated phenomenon. When the adsorption phenomena takes place, i.e. at low temperatures, the formulation described above, represents in a good form the observed mass transport. In this case and as explained above, the transmembrane flux observed is sometimes called "surface flux", $J$. However, at high temperatures when the adsorption phenomena become negligible, the molecules are considered gaseous. In this case, an activated gaseous diffusion, or the so-called translational diffusion takes place. It is described in the GT model by equation 7 :

$$
J^{g}=-\varphi \frac{D^{g}}{R T} \frac{d P}{d z}
$$
as:

where $\varphi$ is a structural parameter and the diffusion coefficient is written

$$
D^{*}=d \sqrt{\frac{8 R T}{\pi M}} \exp \left\{-\frac{E_{a}^{*}}{R T}\right\}
$$

In this way, the transmembrane flux by activated diffusion may be estimated by equation 9 :

$$
J^{g}=-\varphi \cdot d \cdot \sqrt{\frac{8}{\pi \cdot M \cdot R \cdot T}} \exp \left[-\frac{E_{a}^{g}}{R \cdot T}\right] \cdot \frac{d P}{d z}
$$

where $d$ is the mean pore diameter or the diffusion length ${ }^{6}$ and $M$ is the gas molecular weight.

Equation 9 can be rewritten in function of the constants $C_{4}$ and $C_{5}$.

$$
J^{g}=C_{4} \cdot \sqrt{\frac{1}{R \cdot T}} \cdot \exp \left[-\frac{C_{2}}{T}\right] \cdot \overline{\Delta P}
$$

Finally, the flux in activated diffusion is represented by a linear expression:

$$
J^{g}=C_{4} A \cdot B
$$

where $A$ and $B$ are functions of the operation parameters: 


$$
\begin{gathered}
A=\sqrt{\frac{1}{R \cdot T} \cdot \overline{\Delta P}} \\
B=\exp \left[-\frac{C_{5}}{T}\right] \\
C_{9}=\frac{E_{a}^{\varepsilon}}{R}
\end{gathered}
$$

If we consider the gas permeability through a zeolite membrane in a large temperature range we can make the assumption that the total observed flux is a combination of the low- (surface) $J^{s}$ and high-temperature (activated gaseous) $J^{g}$ processes ${ }^{9,13}$. In an earlier work ${ }^{6}$, we explained a total model that represents total flux $\left(J_{t o t}\right)$ in function of two contributions: a first term, represented by the Darken equation applied to surface diffusion for a Langmuir isotherm and an active or translational diffusion term. Then the total flux for one component $\left(\mathrm{CO}_{2}\right.$ in this case) is given by equation 15 :

$$
J_{t o t}=J^{s}+J^{g}=-q_{s a t}, a \varphi \frac{D^{s}}{1-\theta} \frac{d \theta}{d z}-\varphi \frac{D^{g}}{R T} \frac{d P}{d z}
$$

where $\theta$ represents the occupancy of particles on the porous material, $q_{\text {sat }}$ is the concentration of adsorbate under saturation conditions and $D^{s}$ is an intrinsic diffusion coefficient in the Darken equation.

\section{EXPERIMENTAL DETERMINATION OF THE PERMEATION OF DENSE GASES THROUGH MICROPOROUS MEMBRANES}

\subsection{Methodology}

In this study, permeance values of gaseous, near-critical and supercritical carbon dioxide through an MFI zeolite membrane are measured using a transient methodology. In this method the mass transport of dense $\mathrm{CO}_{2}$ through a microporous membrane is estimated using an apparatus working in dead-end configuration.

Two vessels (feed and permeate) are separated by a membrane module. The rate of pressure changes in both vessels will allow evaluating the mass transport through the microporous membrane contained in the module.

This configuration is chosen with the aim to measure low values of permeability and to identify microscopic mechanisms of mass transport in highly selective membranes. Experimental devices operating under a similar principle have been used to evaluate gas permeation at low pressure and represent a simplified and accurate method compared to continuous flow devices that work in a steady state.

\subsection{Experimental device}

The outline of the experimental device used in this work is presented in figure 4. This apparatus is constituted by two vessels: a feed vessel and a permeate vessel separated by a membrane module containing a tubular zeolite supported membrane. The experimental device allows determining the value of flow through the membrane under transient conditions, based on the instantaneous mass values of $\mathrm{CO}_{2}$ in each vessel. Mass values are calculated using Peng-Robinson EOS from the register of pressures and temperatures in function of the time in both vessels. Pressures and temperatures are converted to mass values using an algorithm implemented in the computer connected to the transducers. Changes in instantaneous mass values in function of the time, allow estimating the flow $\left(\mathrm{mol} \mathrm{s}^{-1}\right)$ of $\mathrm{CO}_{2}$ through the membrane. The instantaneous and mean values of flux $\left(\mathrm{mol} \mathrm{s}^{-1} \mathrm{~m}^{-2}\right)$ and permeance $(\mathrm{mol} \mathrm{s}$ $\mathrm{m}^{-2} \mathrm{~Pa}^{-1}$ ) are calculated introducing the surface area of the membrane and the transmembrane pressure respectively.

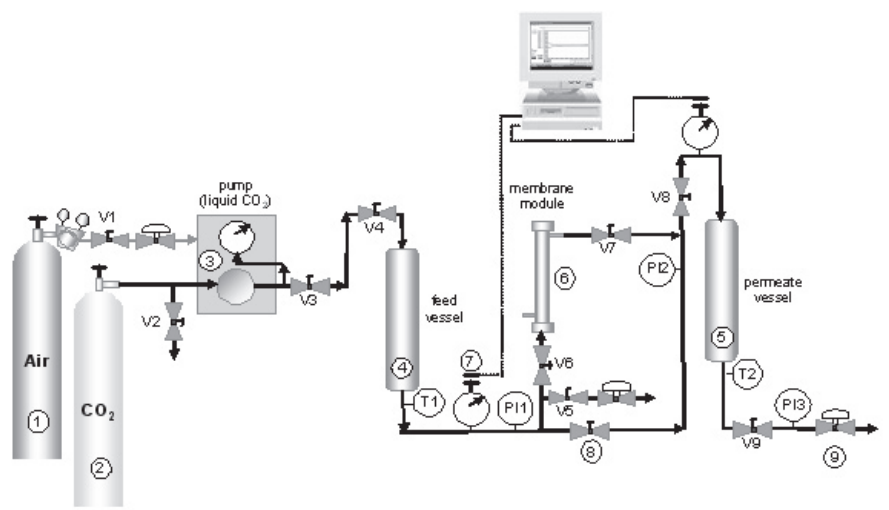

Figure 5. Outline of experimental device designed and used in this work. (1) Air cylinder; (2) $\mathrm{CO}_{2}$ cylinder; (3) air driven pump for liquid $\mathrm{CO}_{2}$; (4) feed vessel; (5) permeate vessel; (6) membrane module; (7) pressure and temperature transducers; (8) by-pass; (9) pressure regulator.

Figure 6 shows a window of the control program during an experimental run.

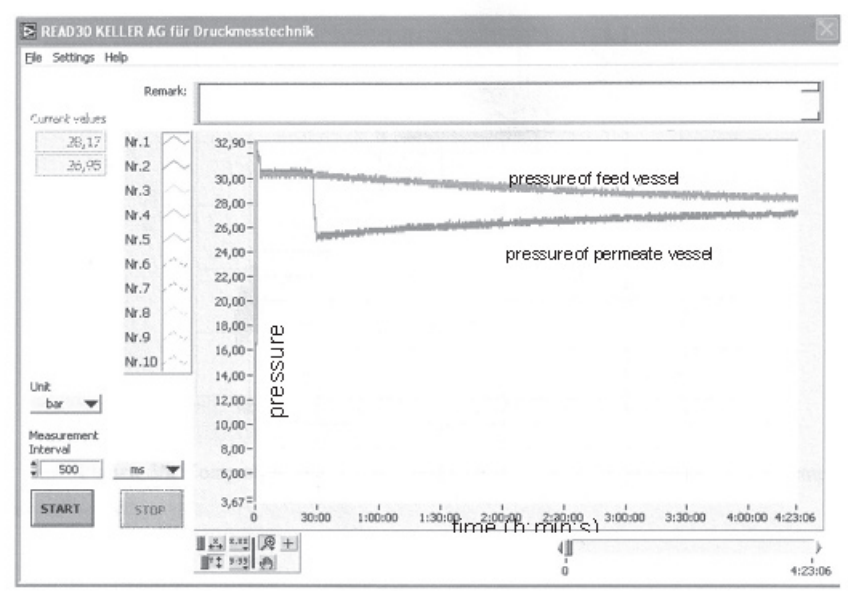

Figure 6. Display screen of the control program recording pressures values in both vessels in function of time.

\subsection{Operation conditions}

Structural parameters of zeolite membrane used in experiments are presented in table 1. These membranes have been synthesized by Julbe and coworkers ${ }^{11}$ by means of a hydrothermal method, crystallizing a zeolite layer on the internal face of a macroporous tubular support of $\alpha-\mathrm{Al}_{2} \mathrm{O}_{3}$.

Table 1. Characteristics of the zeolite membrane used in this work.

\begin{tabular}{|l|c|}
\hline $\begin{array}{l}\text { Structural parameters of the zeolite } \\
\text { membrane }\end{array}$ & Value \\
\hline Geometry & tubular \\
\hline Configuration & $\begin{array}{l}\text { zeolite layer supported on an } \\
\text { alumina tubular membrane in } \\
\text { the internal face }\end{array}$ \\
\hline Structure of zeolite & MFI \\
\hline Length $(\mathrm{m})$ & 0.15 \\
\hline ID $(\mathrm{m})$ & $7^{*} 10^{-3}$ \\
\hline OD $(\mathrm{m})$ & $1^{*} 10^{-2}$ \\
\hline $\begin{array}{l}\text { Effective surface area for mass transfer } \\
\left(\mathrm{m}^{2}\right)\end{array}$ & $2.55^{*} 10^{-3}$ \\
\hline Thickness of zeolite layer $(\mu \mathrm{m})$ & $30-100$ \\
\hline Pore diameter $(\mathrm{nm})$ & $0.53-0.56$ \\
\hline
\end{tabular}


Tables 2 and 3 show the conditions chosen for the experimental design. These variables and its levels have been defined in function of technical limitations in terms of temperature and pressures or in order to obtain a low variability in the experimental runs.

\begin{tabular}{|l|l|}
\hline $\begin{array}{l}\text { Structural parameters of the zeolite } \\
\text { membrane }\end{array}$ & Value \\
\hline Geometry & tubular \\
\hline Configuration & $\begin{array}{l}\text { zeolite layer supported on a } \\
\text { alumina tubular membrane in } \\
\text { the internal face }\end{array}$ \\
\hline Structure of zeolite & MFI \\
\hline Length $(\mathrm{m})$ & 0.15 \\
\hline ID $(\mathrm{m})$ & $7 * 10^{-3}$ \\
\hline OD $(\mathrm{m})$ & $1 * 10^{-2}$ \\
\hline $\begin{array}{l}\text { Effective surface area for mass } \\
\text { transfer }\left(\mathrm{m}^{2}\right)\end{array}$ & $2.55^{*} 10^{-3}$ \\
\hline Thickness of zeolite layer $(\mu \mathrm{m})$ & $30-100$ \\
\hline Pore diameter $(\mathrm{nm})$ & $0.53-0.56$ \\
\hline
\end{tabular}
$\mathrm{CO}_{2}$.

Table 2. Operation conditions in the experimental design using gaseous

\begin{tabular}{|l|c|c|}
\hline Variable & Symbol & Levels in experimental design \\
\hline Feed pressure & $\mathrm{P}_{\mathrm{f}}$ & $3.0 / 4.5 / 5.0 \mathrm{MPa}$ \\
\hline Temperature & $T$ & $50 / 75 / 100^{\circ} \mathrm{C}$ \\
\hline Transmembrane pressure & $\Delta \mathrm{P}$ & $0.5 / 0.75 / 1.0 \mathrm{MPa}$ \\
\hline
\end{tabular}

\begin{tabular}{|l|c|l|}
\hline Variable & Symbol & \multicolumn{1}{|l|}{$\begin{array}{l}\text { Levels in experimental } \\
\text { design }\end{array}$} \\
\hline Feed pressure & $\mathrm{P} 1$ & $3.0 / 4.5 / 5.0 \mathrm{MPa}$ \\
\hline Temperature & $T_{m}$ & $50 / 75 / 100^{\circ} \mathrm{C}$ \\
\hline Transmembrane pressure & $\square \mathrm{P}$ & $0.5 / 0.75 / 1.0 \mathrm{MPa}$ \\
\hline Variable & Symbol & $\begin{array}{l}\text { Levels in experimental } \\
\text { design }\end{array}$ \\
\hline Feed pressure & $\mathrm{P} 1$ & $10 / 12 / 14 \mathrm{MPa}$ \\
\hline Temperature & $T_{m}$ & $50 / 75 / 100^{\circ} \mathrm{C}$ \\
\hline Transmembrane pressure & $\square \mathrm{P}$ & $1.0 \mathrm{MPa}$ \\
\hline
\end{tabular}
$\mathrm{CO}_{2}$.

Table 3. Operation conditions in the experimental design using supercritical

\begin{tabular}{|l|c|c|}
\hline Variable & Symbol & $\begin{array}{c}\text { Levels in experimental } \\
\text { design }\end{array}$ \\
\hline Feed pressure & $\mathrm{P}_{\mathrm{f}}$ & $10 / 12 / 14 \mathrm{MPa}$ \\
\hline Temperature & $T$ & $50 / 75 / 100^{\circ} \mathrm{C}$ \\
\hline Transmembrane pressure & $\Delta \mathrm{P}$ & $1.0 \mathrm{MPa}$ \\
\hline
\end{tabular}

\section{RESULTS}

\subsection{Determining permeation values}

In table 4, mean values of gaseous $\mathrm{CO}_{2}$ flux through MFI zeolite membranes are reported. In this case, permeances have been obtained by means of unsteady-state experiments. Initially, there is no correlation of flux or permeance with operational variables (pressure and temperature).
Table 4. Flux of gaseous $\mathrm{CO}_{2}$ obtained by experiments (mean values) in transient conditions.

\begin{tabular}{|c|c|c|c|c|}
\hline \multirow{2}{*}{ Experiment } & \multicolumn{3}{|c|}{ Initial values of variables } & \multirow{2}{*}{$\begin{array}{c}\boldsymbol{J}_{\text {mean }} \mathbf{1 0}^{\mathbf{3}} \\
\left(\mathbf{m o l ~ m}^{\mathbf{2}} \mathbf{~ s}^{-\mathbf{1}} \mathbf{)}\right.\end{array}$} \\
\cline { 2 - 4 } & $\mathbf{P}_{\mathbf{f}}(\mathbf{M P a})$ & $\mathbf{T}(\mathbf{K})$ & $\Delta \mathbf{P}(\mathbf{M P a})$ & $1.915 \pm 0.136$ \\
\hline 1 & 3 & 323 & 0.5 & $2.905 \pm 0.136$ \\
\hline 2 & 5 & 323 & 0.5 & 2.905 .136 \\
\hline 3 & 3 & 373 & 0.5 & $3.613 \pm 0.136$ \\
\hline 4 & 5 & 373 & 0.5 & $4.150 \pm 0.136$ \\
\hline 5 & 3 & 323 & 1.0 & $4.803 \pm 0.136$ \\
\hline 6 & 5 & 323 & 1.0 & $6.077 \pm 0.136$ \\
\hline 7 & 3 & 373 & 1.0 & $5.560 \pm 0.136$ \\
\hline 8 & 5 & 373 & 1.0 & $8.562 \pm 0.136$ \\
\hline 9 & 4 & 348 & 0.75 & $5.746 \pm 0.136$ \\
\hline
\end{tabular}

On the other hand, values of flux and permeance for $\mathrm{SC} \mathrm{CO}_{2}$ through zeolite membranes are showed in table $\mathbf{5}$. Under supercritical conditions, experimental data are characterized by a bigger variability and the values of permeate flow increase significantly compared to experiments in the gas phase. An increase of permeability at supercritical conditions does not allow an adequate control of the transmembrane pressure to obtain different values in the experimental design. In these experiments, transmembrane pressure was fixed in the initial value of $1.0 \mathrm{MPa}$.

Table 5. Flux of supercritical $\mathrm{CO}_{2}$ obtained experimentally (mean values) in transient conditions for an initial transmembrane pressure of $1.0 \mathrm{MPa}$.

\begin{tabular}{|c|c|c|c|c|}
\hline \multirow{2}{*}{ Experiment } & \multicolumn{2}{|c|}{$\begin{array}{c}\text { Initial values of } \\
\text { variables }\end{array}$} & \multirow{2}{*}{$\begin{array}{c}J_{\text {mean }} \\
\left(\mathbf{m o l ~ \mathbf { m } ^ { - 2 }}\right. \\
\left.\mathbf{S}^{-1}\right)\end{array}$} & \multirow{2}{*}{$\begin{array}{c}\mathbf{G}_{\text {meank }} \mathbf{1 0}^{7} \\
\left(\mathbf{m o l ~ m}^{-2} \mathbf{s}^{-1}\right. \\
\left.\mathbf{P a}^{-1}\right)\end{array}$} \\
\hline & $P_{f}(\mathrm{MPa})$ & $\mathbf{T}(\mathrm{K})$ & & \\
\hline 1 & 10 & 323 & 0.274 & 6.629 \\
\hline 2 & 12 & 323 & 0.266 & 4.756 \\
\hline 3 & 14 & 323 & 0.142 & 3.656 \\
\hline 4 & 12 & 348 & 0.186 & 7.505 \\
\hline 5 & 14 & 373 & 0.120 & 2.244 \\
\hline
\end{tabular}

\subsection{Identification of mass transport mechanism}

In order to evaluate the presence of macroscopic or mesoscopic defaults on the zeolite surface experimental values of flux determined in the range 3-5 MPa were correlated using models applied to macro and mesoporous materials (equations 1 and 2). However, for these models, experimental data were not correctly correlated. According to equation 1, when an exclusive Knudsen like diffusion mechanism is supposed to explain the mass transfer through the membrane, the influence of pressure on the permeance $\left(\mathrm{mol} \mathrm{m}^{-2} \mathrm{~s}^{-1} \mathrm{~Pa}^{-1}\right)$ values must be considered negligible. Tables 4 and 5 show that the values of flux (mol $\mathrm{m}^{-2} \mathrm{~s}^{-1}$ ) and permeance can increase or decrease in function of the operation pressure when the values of temperature and transmembrane pressure remain constant in experiments.

On the other hand, equation 2 describes the influence of pressure and temperature on the value of permeance when viscous flow (Poiseuille) is the predominant mechanism of mass transfer through the membrane. If Poiseuille regime prevails at constant pressure, equation 2 can be simplified to equation 4 . Thus, under this mechanism, the permeance value is inversely proportional to the product of viscosity, $\eta$, and the temperature. Experimental values of permeances obtained in this work shown in table 4 , do not fit equation 4. Experimental values of viscosity of $\mathrm{CO}_{2}$ reported by Sarrade ${ }^{14}$ were considered to test this correlation. In the same way, at constant temperature conditions, equation 2 can be simplified to equation 5 , where permeance becomes proportional to pressure/viscosity ratio. Experimental values of permeance presented in table 4 do not fit equation 5 either.

From experimental data showed in table 4 , it is possible to observe the non-monotonous evolution of the flow in function of pressure and temperature. This behavior cannot be explained by macro or mesoscopic mechanism like Knudsen diffusion or viscous flow.

Only the model for activated diffusion was able to fit all the experimental data presented in table 4. This type of configurational or micropore diffusion can be considered as surface diffusion in the limit where the pore size becomes comparable to the molecular size. In this mechanism, diffusion is perceived as an "activated" process ${ }^{15}$. In this case, separation is strongly dependant on 
molecular shape and size, pore size and the interactions between the pore wall and gas molecules.

Figure 7 shows the correlation between experimental values of flux and the parameters $A$ and $B$ proposed in equation 11 by means of a linear relationship. The better correlation was observed for a value of activation energy $E_{a}{ }^{g}=3.33$ $\mathrm{kJ} \mathrm{mol}^{-1}$.

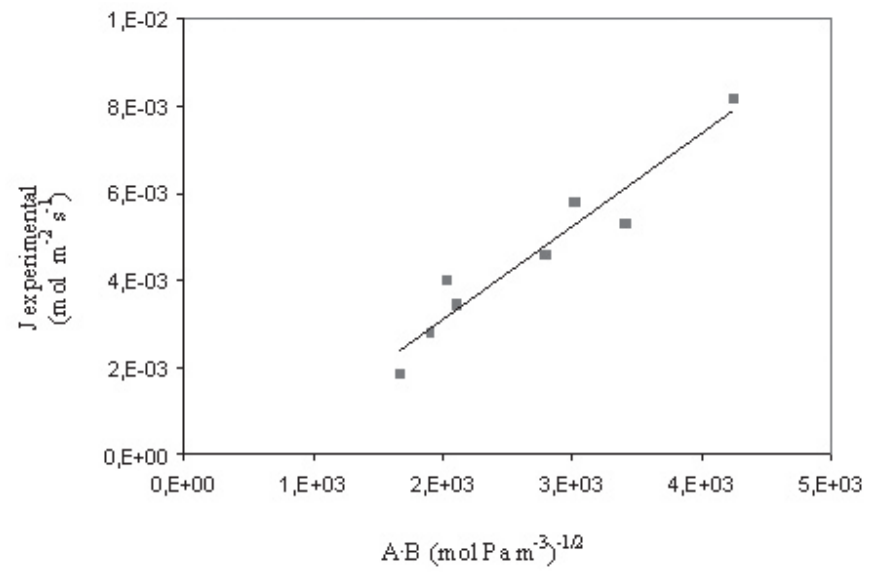

Figure 7. Correlation of flux values obtained by experiments for gaseous $\mathrm{CO}_{2}$ through a MFI zeolite membrane using activated gaseous diffusion model (equation 6) for $E_{a}^{g}=3.33 \mathrm{~kJ} \mathrm{~mol}^{-1}$.

Activated diffusion through microporous membranes occurs by solid state diffusion of molecules. The permeation flux in equation 7 has been derived by other authors ${ }^{15}$ from the Fick's first law:

$$
J=-\bar{D} \frac{d C}{d z}
$$

where $\overline{\mathrm{D}}$ is the chemical diffusion coefficient, $\mathrm{C}$, the local concentration of molecules and $\mathrm{z}$, the coordinate along the permeation direction.

Normally, this configurational diffusion is assumed to be the ratecontrolling step. Therefore, gas phase diffusional resistance is negligible, and thermodynamic equilibrium can be assumed at the interface. The concentrations of molecules at both membrane surfaces can be described by Henry's law equation:

$$
C=S \cdot P
$$

where $\mathrm{S}$ is a proportionality constant that depends on temperature according to:

$$
S=S_{0} \exp \left(-\frac{\Delta H_{s}}{R T}\right)
$$

where $\mathrm{S}_{0}$ is a temperature independent proportionality constant, $\Delta \mathrm{Hs}$, the isosteric heat of adsorption, R, the gas constant and $\mathrm{T}$, the absolute temperature. The validity of Henry's law implies that the concentration of molecules adsorbed in the microporous solid is small compared to the number $\therefore$ Ivailable sites (pores). In the Henry's (or Langmuir) law adsorption regime, $\mathrm{D}$ is independent of concentration ${ }^{15}$. Its temperature dependence is given by:

$$
\bar{D}=\overline{D_{0}} \exp \left(-\frac{E_{D}}{R T}\right)
$$

where $\overline{\mathrm{D}}_{0}$ is a temperature independent proportionality constant and $\mathrm{E}_{\mathrm{D}}$, the positive mobility energy. According to atomic jump theory ${ }^{16}, E_{D}$ represents the energy barrier between two adjacent sorption sites.

$\operatorname{Re}:-\bar{D}$ nement of equations 16 to 19 and then integration with the condition that $\mathrm{D}$ is independent of $\mathrm{C}$ yield:

$$
J=\bar{D}_{0} S_{0} \exp \left(-\frac{\Delta H_{s}+E_{D}}{R T}\right) \frac{P_{f}-P_{y}}{\delta}=J_{0} \exp \left(-\frac{E_{a}^{g}}{R T}\right) \frac{P_{f}-P_{y}}{\delta}
$$

where $P_{f}$ and $P_{p}$ are the operating pressures at up (feed) and down (permeate) streams respectively. $\delta$ is the membrane thickness.

Coefficient $\mathrm{J}_{0}$ in equation 20 represents a temperature independent proportionality constant defined as:

$$
J_{0}=\overline{D_{0}} S_{0}
$$

and $\mathrm{E}_{\mathrm{a}} \mathrm{g}$ is the effective activation energy for permeation defined as:

$$
E_{g}^{g}=\Delta H_{5}+E_{D}
$$

Equation 22 provides the physical significance of the effective activation energy obtained in this work $\mathrm{E}_{\mathrm{a}}^{\mathrm{g}}$ (equation 8 ) as a combined effect of adsorption and diffusion in the pore.

\subsection{Permeation values at high pressure conditions}

In the range 10-14 MPa, the correlation between experimental data and the equation 6 has not been identified. The increase of flux observed can be the result of defaults formation. Indeed, these defaults can be macro and/or mesopores formed after the increase of pressure behind the critical point. This increase of permeability was irreversible even after the degasification of the membranes under vacuum conditions, which leaves in evidence a deterioration of the toplayer. Another possibility to explain the increase of permeance through zeolitic membranes is a modification in crystalline structure of the zeolite membrane, but this phenomenon has been reported by some authors ${ }^{6,17}$ when the temperature is greater than $373 \mathrm{~K}$, which is the maximum value considered in this work. In fact Webster and coworkers ${ }^{17}$ have demonstrated that the effective pore size of HZSM-5 in reaction conditions increased from 6.62 to $7.64 \AA$ when the temperature increased from 573 to $643 \mathrm{~K}$.

If the top layer presents deterioration at high pressure conditions, the mass transfer can be controlled by simultaneous macro and microscopic mechanisms like viscous flow, Knudsen like diffusion and activated diffusion (equations 1, 2 and 9).

\section{CONCLUSIONS}

A new experimental system using a transient methodology has been developed to evaluate the permeance (and potentially selectivity) of dense gases, liquids and supercritical fluids through microporous membranes. From the experiments flux and permeance of $\mathrm{CO}_{2}$ at high pressure conditions have been calculated and the obtained values are coherent with the mass transport properties through micropores. Indeed, the experimental permeability can not be described by classical mechanisms (Knudsen like diffusion or viscous flow).

This new experimental device allows estimating permeance values between $3.59_{*} 10^{-9}$ and $7.51{ }_{*} 10^{-7} \mathrm{~mol} \mathrm{~m}^{-2} \mathrm{~s}^{-1} \mathrm{~Pa}^{-1}$ when the values of feed pressure are between 3 and $14 \mathrm{MPa}$ and the temperature varies between 25 and $100^{\circ} \mathrm{C}$.

For experiments between 3 and $5 \mathrm{MPa}$ there is not a direct correlation between permeance values and operation variables (pressure and temperature). In this case, experimental data may be correlated using equation 11, explaining mass transfer by means of an activated or translational diffusion of $\mathrm{CO}_{2}$ in micropores. This study represents the first report of this type of mechanism in micropores under high pressure conditions.

At supercritical conditions, permeability of $\mathrm{CO}_{2}$ through zeolite membranes increases significantly compared to values at gaseous conditions. This behavior may be explained by a limited resistance of the top layer at high pressure conditions involving the mass transfer through macroscopic or mesoscopic defaults on the zeolite membrane.

In a next step, future experiments will be developed to estimate the selectivity in this type of membranes in order to identify mechanisms of mass transfer from the separation of mixtures.

\section{ACKNOWLEDGEMENTS}

This work was supported by FONDECYT (CONICYT Chile) - Projects 1040240 and 1070062 - and the Franco-Chilean cooperation Project ECOSCONICYT C04 E06 (France-Chile). The financial support for these projects is gratefully acknowledged. 


\section{NOMENCLATURE}

\begin{tabular}{|c|c|c|}
\hline Symbol & Description & Units \\
\hline A & Constant in equation 12 & $\left(\mathrm{~mol} \mathrm{~Pa} \mathrm{~m}^{-3}\right)^{1 / 2}$ \\
\hline$A_{k}$ & Structural parameter in equations 1 and 2 & dimensionless \\
\hline $\mathrm{B}$ & Constant in equation 13 & dimensionless \\
\hline $\mathrm{C}$ & Constant in equation 6 & $\mathrm{~mol} \mathrm{~Pa}^{-1} \mathrm{~m}^{-2} \mathrm{~s}^{-1}$ \\
\hline $\mathrm{C}_{1}$ & Constant in equation 3 & $\mathrm{~mol} \mathrm{~K}^{1 / 2} \mathrm{~m}^{-2} \mathrm{~s}^{-1} \mathrm{~Pa}^{-1}$ \\
\hline $\mathrm{C}_{2}$ & Constant in equation 4 & $\mathrm{~mol} \mathrm{~K} \mathrm{~m}^{-2}$ \\
\hline $\mathrm{C}_{3}$ & Constant in equation 5 & $\mathrm{~mol} \mathrm{~m}^{-2} \mathrm{~Pa}^{-1}$ \\
\hline $\mathrm{C}_{4}$ & Constant in equations 10 and 11 & $\left(\mathrm{~mol} \mathrm{~m}^{-1} \mathrm{~s}^{-2} \mathrm{~Pa}^{-1}\right)^{1 / 2}$ \\
\hline $\mathrm{C}_{5}$ & Constant in equations 13 and 14 & $\mathrm{~K}$ \\
\hline $\mathrm{D}$ & Diffusion coefficient & $\mathrm{m}^{2} \mathrm{~s}^{-1}$ \\
\hline d & mean pore diameter or the diffusion length & $\mathrm{m}$ \\
\hline $\mathrm{E}_{\mathrm{a}}$ & Activation energy & $\mathrm{J} \mathrm{mol}^{-1}$ \\
\hline $\mathrm{F}_{\mathrm{k}}$ & Characteristic parameter of the membrane in equations 1 and 2 & dimensionless \\
\hline$F_{p}$ & Characteristic parameter of the membrane in equations 1 and 2 & dimensionless \\
\hline $\mathrm{G}$ & Permeance & $\mathrm{mol} \mathrm{m} \mathrm{m}^{-2} \mathrm{~s}^{-1} \mathrm{~Pa}^{-1}$ \\
\hline $\mathrm{J}$ & Transmembrane flux & $\mathrm{mol} \mathrm{m}^{-2} \mathrm{~s}^{-1}$ \\
\hline $\mathrm{M}$ & Molecular weight of the transferred compound & $\mathrm{kg} \mathrm{mol}^{-1}$ \\
\hline $\mathrm{P}_{\mathrm{f}}$ & Feed pressure & $\mathrm{Pa}$ \\
\hline $\mathrm{P}_{\mathrm{m}}$ & Mean value of pressure & $\mathrm{Pa}$ \\
\hline$P_{p}$ & Permeate pressure & $\mathrm{Pa}$ \\
\hline Qa & Adsorption heat in equation 6 & $\mathrm{~J} \mathrm{~mol}^{-1}$ \\
\hline $\mathrm{q}_{\mathrm{sat}}$ & Saturation surface concentration & $\mathrm{mol} \mathrm{m}^{-3}$ \\
\hline $\mathrm{R}$ & Universal constant of gases & $\mathrm{J} \mathrm{mol}^{-1} \mathrm{~K}^{-1}$ \\
\hline$r_{p}$ & Pore radius & $\mathrm{m}$ \\
\hline $\mathrm{T}$ & Temperature & $\mathrm{K}$ \\
\hline \multicolumn{3}{|c|}{ Greek symbols } \\
\hline$\Delta \mathrm{z}$ & Thickness of the membrane & $\mathrm{m}$ \\
\hline$\varphi$ & Structural parameter in equation 7 & dimensionless= \\
\hline$\eta$ & Dynamic viscosity & $\mathrm{Pa} \mathrm{s}$ \\
\hline$\rho$ & Density & $\mathrm{kg} \mathrm{m}^{-3}$ \\
\hline$\theta$ & Occupancy & dimensionless= \\
\hline \multicolumn{3}{|c|}{ Superscripts } \\
\hline $\mathrm{g}$ & Related to activated diffusion & \\
\hline Knudsen & Related to Knudsen diffusion & \\
\hline Poiseuille & Related to viscous flow & \\
\hline $\mathrm{s}$ & Related to surface diffusion & \\
\hline
\end{tabular}

\section{REFERENCES}

1) Sarrade, S., Guizard, C. and Rios, G., Desalination 144, 137-142 (2002).

2) Semenova, S., Ohya, H., Higashijima, T. and Negishi, Y., J. Memb. Sci., 74, 131 (1992).

3) Sartorelli, L. and Brunner, G., Proceedings of the 5th International Symposium Supercritical Fluids. Atlanta, USA (2000).

4) Bothum, G., Knutson, B., Strobel, H., Nokes S., Brignole, E. and Diaz, S., J. Supercritical Fluids, 25, Issue 2, 119-134 (2003).

5) Romero J., Le Cam, S., Sanchez, J., Saavedra, A. and Rios, G., Chem. Eng. Sci., 56, 3139-3148 (2001).

6) Romero, J., Gijiu, C., Sanchez J., and Rios, G., Chem. Eng. Sci., 59, 1569-1576 (2004).

7) Patil, V., Meeuwissen, J., Leo J.P. van den Broeke, L. and Keurentjes, J., J. Supercritical Fluids, 37, Issue 3, 367-374 (2006).

8) Mulder, M., Basic Principles of Membrane Technology, Kluwer Academic Publishers, Amsterdam, 1998.

9) Burggraaf, A., Fundamentals of inorganic membrane science and technology, In: Burggraff, A., Cot, L. (Eds.). Membrane Science and Technology Series 4. Elsevier, Amsterdam, 1996.
10) Van de Graaf, J., Kapteijn, F. and Moulijn, J., Microporous and Mesoporous Materials, 35, 267 (2000).

11) Julbe, A., Farrusseng, D., de Ménorval, L.C., and Guizard, C., Sep. Purif. Tech., 32, Issues 1-3, 165-173 (2003).

12) Sarrade, S, Rios, G.M., and Carlés, M., J. Memb. Sci., 114, 81-91 (1996).

13) Van der Broeke, L., Bakker, W., Kapteijn, F. and Moulijn, J., Chem. Eng. Sci., 54, 245 (1999).

14) Sarrade, S., Etude du couplage de l'extraction par CO2 supercritique avec la séparation par membrane de nanofiltration. Doctoral Thesis, University of Montpellier - France, 1994.

15) Li, K., Ceramic membranes for separation and reaction, John Wiley \& Sons Ltd, Chichester, 2007.

16) Rangarajan, R., Mazid, M.A., Matsuura, T., and Sourirajan, S., Ind. and Eng. Chem. Process Design and Development, 23, 79-87 (1984).

17) Webster, C.E., Drago, R.S., and Zerner, M.C. J. of Physical Chemistry B, 103, 1242 (1999).

18) Giroir-Fendler, A., Julbe, A., Ramsay, J.D.F., Dalmon, J.A., French patent (CNRS) no. 94-05562-PCT Int. Appl. FR 94-0429.

19) Cot. L., Ayral, A., Durand, J., Guizard, C., Hovnanian, N., Julbe, A., and Larbot, A., Solid State Sci., 2, 313-334 (2000). 